\title{
ГРАММАТИКО-СЕМАНТИЧЕСКАЯ ТИПОЛОГИЯ ГЛАГОЛОВ. ВОЗВРАТНЫЕ НОВАЦИИ В СОВРЕМЕННОМ РУССКОМ ЯЗЫКЕ
}

\author{
ВЛАДИМИР Н. ШАПОШНИКОВ \\ Московский государственный психолого-педагогический университет \\ Факультет иностранных языков \\ Кафедра лингводидактики и межкультурной коммуникации \\ ул. Василия Ботылева, д. 31, 121500, Москва, пос. Рублево, Россия \\ e-mail: vladimirshaposhnikoff@yandex.ru \\ (получено 16.08.2017; принято 27.09.2017)
}

\section{Abstract \\ Grammar-semantic Typology of Verbs. Innovations of Reflexives in Contemporary Russian}

In the article, the grammatical-semantic typology of verbs is considered. The morphosyntactic classes of verbs in the contemporary Russian language are noted. The reflexive verbs and the principles of their description are analyzed. New phenomena of reflexivity and its types in the Russian language are described, based on the semantic, derivational and syntactic criteria.

\section{Key words}

Verb, verb typology, reflexive verbs, grammatical-semantic classes, language changes.

\section{Резюме}

Рассматривается грамматико-семантическая типология глаголов. Выделяются морфосинтаксические классы глаголов в современном русском языке. Анали- 
зируется область возвратных глаголов, принципы их описания. Описываются новые явления возвратности и их типы в русском языке, выделяемые по логикосемантическому, деривационному и структурно-синтаксическому основаниям.

\section{Ключевые слова}

Глагол, типология глаголов, возвратные глаголы, грамматико-семантические классы, языковые изменения.

Многообразная структура языка и языковая семантика, ее развитие включает различные по положению части и элементы. В языковой организации содержание глагола сосредоточивает самый богатый набор грамматических категорий; он представляет целую процессуальную ситуацию, семантическими компонентами которой наряду с действием являются различные номинативные участники. Парадигма глагола охватывает различные аспекты языковой структуры. В грамматической системе выделяются глагольные типы, которые объединяются групповыми номинативными значениями и выражают их избранными и сопоставленными формальными средствами. Система и структура языка характеризуется тем, что общий состав этих способов глагольного действия окончательно не установлен. Данные номинативно-грамматические разряды способы действия - связаны с системой грамматических категорий. По своей природе это семантико-морфологические, лексико-грамматические общности языковых единиц.

При описании структуры языка выделяются по присущим глаголам грамматическим связям синтактико-семантические классы, которые имеют типовые значения и общие категориальные управляющие и синтаксические трансформационные свойства. При их внутренней соотнесенности синтаксические свойства глаголов не только служат основанием для формирования семантических классов, но и основой для предсказания управляющих свойств глаголов ${ }^{1}$. В принципе отмечается ${ }^{2}$, что синтактико-семантические классы глаголов связаны с морфологическими категориями: видом, залогом, наклонением и временем. Принадлежность к выделяемому лексико-грамматическому классу формирует определенные закономерности количества, состава и ранга семантических отношений - актантов глагола.

В современном русском языке возникают новые по конструктивным составляющим признаками типовые явления лексико-грамматического материала. Развиваются новые типовые явления особой структурно-семантической области - возвратных глаголов. Содержание возвратных глаголов является сложным феноменом, трудным для логического определения. Сложность проявля-

\footnotetext{
1 Теоретические проблемы русского синтаксиса. Отв. ред. Ю.Д. Апресян. Москва: Языки славянских культур, 2010, с. 289.

2 Ю.Д. Апресян. О толковом словаре управлений и сочетаемости русского глагола. [В:] Словарь, грамматика, текст. Москва: Институт русского языка им. Виноградова, 1996, с. 21.
} 
ется в их группировке. Ср. отмечавшиеся группы возвратных глаголов от пяти основных (собственно-возвратные, взаимно-возвратные, активно-безобъектные, косвенно-возвратные, общевозвратные) до десяти и более групп³. Возвратные группы выделяются не всегда под теми же названиями.

Вся данная структурная область характеризуется тем, что объективно происходит соединение и смешение принципов описания возвратных глаголов, - отмечаемых логико-семантического и деривационного подходов в их изучении. Так, собственно возвратные и активно-безобъектные возвратные глаголы выделяются по значению, привнесенному аффиксом -ся; общевозвратные и взаимно-возвратные глаголы выделяются по лексическому значению глагола; безличные возвратные глаголы выделяют на иносистемном для морфологии синтаксическом основании отсутствия подлежащего 4

Исследовательское совмещение подходов обусловливается эмпирически грамматическим материалом языка. Полное описание возвратных глаголов вынуждено учитывать как те формальные отношения, которые связывают возвратный глагол с его производящим невозвратным, так и те смысловые связи, которые существуют между различными возвратными глаголами. Русские возвратные глаголы образуют сложную сеть, в которой выявляются конструктивные планы - деривационный и собственно семантический, а также структурносинтаксический аспект языковых единиц.

В целом возвратные глаголы семантически и структурно весьма неоднородны. Неоднородность приводит к трудности и противоречиям в определении возвратных глаголов. Глаголы по-разному включаются и трактуются в их группировках. Так, в одной приводившейся классификации в группе рефлексивнопосессивных указываются глаголы «прищуриться, публиковаться» ${ }^{5}$. Однако по внутреннему семантическому признаку субъектной и объектной локализации действия они различны, в силу чего могут быть отнесены к разным лексикограмматическим группам. Аналогично, трактуемые как пассивно-качественные глаголы «читается, запирается» различаются по субъектному и объектному признакам действия. Ср. преобразование: читается, напр., Флешка не читается; смотреться, напр., Вообще-то фильм смотрится (газета «Маяк», 01.07.2016); стираться (1. Пиджак стирается, изделие не стирается, т. е. можно/нельзя стирать; 2. Материал стирается, т. е. возможно отстирать); гладиться, напр., Ткань не гладится.

Неоднородность глаголов связана с природой возвратного показателя -ся, который занимает конструктивно промежуточное положение среди типов морфем. Постфикс -ся по базовой характеристике - отношению значения морфемы к значению целого, в состав которого она входит, - находится между типом морфем, значение которых прямо и непосредственно входит в значение целого,

3 Ю.П. Князев. Русские возвратные глаголы на семантической карте реблексивности. [В:] Грамматические процессы и системы в синхронии и диахронии. Ред. колл. А.М. Молдован и др. Москва: Институт русского языка им. В.В. Виноградова РАН, 2016, с. 34.

4 Русская грамматика. Т. 1. Ред. Н.Ю. Шведова. Москва: Высшая школа, 1980, с. 279.

5 Ю.П. Князев. Русские возвратные глаголы..., с. 35. 
и морфемами, чье значение только косвенно и опосредованно входит в значение целого.

Как и существовавшие группы материала, новые явления возвратности и их разновидности выделяются и группируются в зависимости от конструктивных показателей определенных языковых уровней: типа лексического значения, словообразовательной связи глагола, характера синтаксических связей в предложении и соответствующего им внутриструктурного соотношения семантических и синтаксических актантов глагола.

\section{I. Субъектно-результативный тип глаголов. Приставочные глаголы с определенным значением. Совершенный вид.}

3acветumbя. Ранее глагол представлял собой начинательный тип семантики (оказаться под освещением, стать объектом физического действия со стороны). Ср. толкование $\mathrm{MAC}^{6}$ : Засветиться. 1. - над, 2. - чем. Представляется другой тип действия по сравнению с семантикой существовавшего глагола - 'достичь известного состояния': 1) Фьюджит уже успел засветиться в паре десятков фильмов и сериалов (газета "Metro", 15.06.2016); 2) Совершенный и несовершенный вид в значении совершенного вида: Чубик также не захотел засвечиваться (В.С. Маканин. Андеграунд, или Герой нашего времени, 1998).

Конструктивные параметры нового глагола следующие: изменение субъекта действия - одушевленный предмет; изменение структуры семантики - активный процесс; устранение определяющего компонента значения - начала действия и его сосредоточенности; изменение управления (семантического компонента пространства) - где; устранение орудийной связи - чем; устранение структурной связи со значением пространства; приобретение качественно-результативной связи, т. е. обозначение цели и результата действия; обозначение производителя действия - продвижение в новое состояние и включение нового качества.

Аналогичны по типу значения, словообразовательной структуре, характеру синтаксических связей и внутреннему соотношению семантических и синтаксических актантов глаголы: подвинуться, просторечное, напр., подвинулся рассудком; сдвинуться (Убогий бомж... сдвинулся на Осе Мандельштаме. Ю. Кузнецов); прокапаться, напр., Я сейчас прокапаюсв и пойду на другие процедурь; пролечиться, напр., Надо пролечиться. Потом будет ясно; пронаблюдаться, напр., Пронаблюдаться у специалиста; выдвинуться, напр., 304 кандидата въцвинулись самостоятельно; избираться, напр., Он в ноябре избирается; обсудиться, напр., Он обсудился на кафедре.

\footnotetext{
6 МАС - здесь и далее: Малый академический словарь. Ред. А.П. Евгеньева. Москва: Русский язык, 1981-1984.
} 
При образовании этого типа возникает омонимия, как то: проколоться I. (напр., Ть там прокололся, т. е. допустил оплошность); проколоться II. (напр., Проколетесь, потом придете на прием).

Внутри грамматико-семантического типа выделяются разновидности и более мелкие подгруппы. Новые глаголы соотносятся с существительными, то есть семантика мотивирована предметом: защититься, напр., Он защитился недавно; пропиариться; освободиться, напр., Я в прошлом голу освободился; демобилизоваться; призываться, напр., Я призывался в Саратове; светиться, скажем, Не надо там светиться (устная речь, 2001); остепениться, напр., остепененные преподаватели; разговорные одоцентиться и предзащититься; просторечные устаканиться, остограмиться, остаканиться, ополлитриться.

Морфемная, приставочно-суффиксальная структура глаголов этого типа соответствует их семантике и синтаксическим свойствам. По типу семантики это не автокаузативные глаголы, не собственно причинные по внутреннему строению содержания. Ср. пример последних: Андрей спрятался за высоким памятником; Они летели вместе <...> и там познакомились ${ }^{7}$. В определении семантики автокаузативных глаголов субъект полностью обусловливает действие и является его единственной исчерпывающей причиной, что не тождественно содержанию образующихся глаголов субъектно-объектно-результативного типа, обозначающих стороннего содействователя, для которого субъект является объектом. Субъектно-результативные глаголы также отличаются от внешне похожих глаголов собственно возвратного типа, которые обозначают физическое действие, направленное на самого деятеля и совершаемое им самим в своих интересах. Образовавшиеся глаголы соотносятся с трактовкой рефлексивнопосессивной группы, то есть возвратно-притяжательными глаголами. Однако в дополнение к тому содержанию, в выделяющихся субъектно-объектных новациях субъект производит действие и при этом результат является объектом некоторого процесса; таким образом действие возможно под влиянием другого, стороннего источника, и субъект изменяется под влиянием действия. Субъектно-результативный тип несколько отличается от выделявшихся рефлексивнокаузативных глаголов: завербоваться, казаться, жениться ; ср. также сдаться, отметиться. Таким образом, у субъектно-объектно-результативной лексемы иное соотношение семантических и синтаксических актантов: деятеля - подлежащего, объекта и пациенса - дополнения.

На общей карте рефлексивности, концептуальной схеме представления возвратности в современной грамматической теории, основанной на принципах непрерывности и смежности значений ${ }^{9}$ в грамматической системе эти глаголы более удалены от области пассива - правой части карты и сдвинуты к ее противоположной левой части, крайняя точка которой маркируется формой

\footnotetext{
7 Ю.П. Князев. Русские возвратные глаголь..., с. 35.

8 Там же, с. 34.

9 M. Haspelmath. The geometry of grammatical meaning: semantic maps and cross-linguistic comparison. [B:] The new psychology of language. V. 2. Mahwah, NJ: Erlbaum, 2003, c. 96.
} 
английского языка himself, но после срединной части, показываемой формой французского языка se.

Глаголы данного типа соотносительны с глаголами без постфикса -ся, которые являются переходными. Функции морфемы -ся в образованных глаголах двойственны, прямо входя в значение целого - слова и относясь к значению синтаксической единицы.

\section{II. Субъектно-страдательный тип (агентивный пассив).}

Первоначально этим способом преобразовывались бесприставочные глаголы. Они формально соотносительны с глаголами без постфикса -ся, переходными, т.е. управлявшими объектным значением.

Семантика этого типа образуется в измененных компонентах: субъект действия становится объектом воздействия и в силу этого изменяется.

Вестись / Повестись. Разговорное. Действительный залог.

Образуется семантическая связь контрагента - на что, либо глагол без дополнения - обозначения участника ситуации: Главное на это не вестисв, типа нет никого (В. Дурненков. Мир молится за меня, 2005); Молодой партийньй функиионер повелся на эту провокаторшу-проститутку («Литературная газета» 2016, № 42).

Купиться / Покупаться. Например, Как люди могут покупаться на соболиную шубу для жень и мерседес для сына (В. Громов. Компромат для олигарха, 2000).

Тащиться. Просторечное. Образован от переходного глагола: Он тащится с нее (устная речь).

Подставиться / Подставляться. Разговорное.

Одновалентный глагол с главной субъектной связью. Он образован от переходного трехвалентного глагола подставить, который был семантически преобразован в связи с объектом, ставшим одушевленным, и изменен структурносемантически.

Напрягаться. Просторечное. Несовершенный вид: Я один доедал суп, напрягался (устная речь). Одноактантный глагол, одна валентность которого является разорванной. Цепь семантического преобразования: напрягать, что $\rightarrow$ напрягать, кого $\rightarrow$ напрягаться. Происходит изменение акциональности, степени действия в содержании глагола.

Все эти глаголы могут иметь валентность причинно-следственной связи, но являются информационно полными и сами по себе.

\section{III. Субъектно-целевой тип.}

Догнаться / Догоняться. Просторечное. Новообразование. Совершенный и несовершенный вид: Они там сидели, догонялись; Надо догнаться; Догонимся (устная речь). 
Структура появившегося значения: 'изменить себя' плюс 'достичь состояния’. В соответствии с ней появляется косвенная валентность - творительный падеж орудийного значения: Они догонялись пивом (устная речь, 2001).

Оттянуться / Оттягиваться.

Формально исходный глагол тянуться и производный от него протянуться включает в свое содержание параметрический компонент и насчитывает в своей структуре до 4 валентностей: объект (что тянется), направление (куда), путь (через что, между чего, по чему, вдоль чего) и расстояние (на сколько). Первая из этих позиций характеризуется тем, что ее может заполнять субъектная валентность. Появившийся затем глагол физического действия оттянуться имел значение 'отвиснуть', разговорное. В нем произошло упрощение структуры валентностей.

Имевшиеся семантические валентности устранились во внутренней перестройке новообразования. Обязательной главной валентностью становится субъектная: Mь оттягивались. У семантического новообразования появились другие структурные связи: Потом $\leftarrow$ мы оттянемся $\rightarrow$ по полной (устная речь), т.е. семантические роли времени и образа действия.

Сформировалось второе значение данного глагола, при котором имеется новая валентность пациенса: оттянуться - на ком / чём.

Оторваться. Просторечное. Одновалентный глагол, напр., Никто не отmягивается так, как русские (Интернет, 2016).

Эти возвратные глаголы образованы от переходных глаголов с развитой системой актантов, которые устраняются. В общем этот семантический тип отличается от собственно возвратных глаголов (умьвваться, подготовиться), которые обозначают физическое действие, направленное деятелем на себя и на нем сосредоточенное. Данные же глаголы обозначают действие, направленное на результат, которое прикладывается не к границе, а к некоторой находящейся на развитой стадии состояния точке.

\section{IV. Объектно-целевой тип.}

Его создают приставочные глаголы, образованные от бесприставочных возвратных глаголов, которые образованы в свою очередь от переходных, т.е. имевших прямой объект глаголов.

Позаниматься. Совершенный вид в значении несовершенного. Действительный залог - 'заняться деятельностью, обратиться к деятельности': Может, логистикой позанимаемся? (газета, 2015); Я вчера позанимался, поизучал этот закон (ТВ, 2016). Ср. ранее: Позанимайся с ним (Чехов). Происходит устранение семантического актанта пациенса; устранение актанта взаимодействия, выражавшегося творительным падежом с предлогом. Устраняется также компонент одушевленности в управлении; устраняется в значении компонент 'некоторое время, немного'; наличие связи (косвенного) объекта - чем.

Структура значения равнозначно 'действие в определенном направлении', 'стремление к участию'. 
Показатель лимитатива присоединяется к названию процесса - обозначению самопроизвольного изменения объекта; процесс представляется как ситуация. Видовое значение включает как качественную, так и количественную аспектуальность, а также совмещается с неаспектуальным значением.

Побиться. Совершенный вид в значении несовершенного, напр., A. Поветкин побьется за претендента (газета «Коммерсантъ-Daily», 09.04.2015; далее - газета «Ђ»). Устранение актанта взаимодействия в форме творительного падежа с предлогом - с кем; наличие целевой валентности - за что.

Побороться. Совершенный вид в значении несовершенного: Мы решили побороться за вашу ногу (2004); За пост канилера поборется М. Шульи, (ТВ, 2017).

Преобразование: обозначение субъекта-деятеля в 3 лице; появление целевой валентности - за что; устранение в значении компонента взаимности.

Поругаться. Совершенный вид в значении несовершенного.

1. Я с ним поругался. Разговорное, в значении 'рассориться'.

2. Вы пришли поругаться? В значении 'делать перепалку, схватиться'.

Подраться.

1. Не подрались? (устная речь). Разговорное.

2. Совершенный вид в значении несовершенного: Что, хочешь подраться? В значении 'вступить в схватку'.

Пободаться. Просторечное. Одновалентный глагол: обозначает действие с компонентом 'на необходимом и достаточном уровне'. Например, Поставили канадиев, поверивших, что способны пободаться, на место (газета «Ђ», 18.08.2016).

Эти глаголы не имеют значения взаимности. Ср. с новообразованиями невозвратного приступательно-перфектного типа: поучаствовать, попривыкать, пообсуждать.

\section{V. Объектно-итоговый тип. Совершенный и несовершенный вид.}

Получается / Получиться. Например, В Европу не получается? (А. Битов); Нет, $к$ Новому году не получится (Р. Сенчин); Зато получилось поучаствовать в конкурсе.

В содержании новообразования синтактико-семантические планы: действие, сосредоточенное в самом себе, направлено на объект и при этом имеет субъектную перспективу - соединяются. Происходит изменение структурносемантических связей слова. Изменяется субъект-объектный компонент в содержании новообразования. Например, С фаготом, все-таки, кажется, полуиается закончить (Р. Сенчин. Чего вы хотите?, 2013).

Оформляется сирконстант 'способ'. Оформляются те или иные сирконстантные связи, в том числе значение меры и степени. Например, Поговорить об этом стихотворении и о поднятых в нем проблемах почти не получилось - пришел брат Алеша (Р. Сенчин).

Случиться. Совершенный вид. 
В лексико-грамматической системе глагол был импликативным, представляющим своим содержанием два выражаемых и соединяемых понятия. На данной логико-синтаксической основе происходит семантическое новообразование: С началом строчтельства «Южного потока», которое случится завтра, <...> (газета «Ђ», 06.12.2012); Потом случилась роль; Случилась любовь (газетное интервью) в значении 'прийти, явиться'.

Субъект устраняется из содержания: Вначале планировалась встреча Путина с единоросами <...> Не случилось. Зато... («Российская газета», 10.08.2014); Сразу не случилось, пищу только сейчас (Интернет, 2015).

Лексема передвинулась в данный структурно-семантический класс, переходя границы сферы действия, а именно: изменение представления субъекта-деятеля; изменение представления объекта действия - конкретный предмет; изменение в содержании компонента акциональности - его увеличение.

Сложиться. Совершенный вид.

Например: Не сложилось на курорте, зато... («Российская газета», 23.06.2014); Как сложится (устная речь); С Красной Поляной не сложилось (Интернет, 08.02.2016); Если все сложится, <...> индийцы получат долю пирога в кинопрокате (газета «Культура», 2017, № 5).

Это значение слова представляет опору на структурную схему другого, предшествующего предложения и на внеязыковую ситуацию. Один актант в разных употреблениях заполняет разные синтаксические функции и семантические роли.

Задаться. Разговорное. Например, Но с правовой основой, кажется, не задалось с самого начала («Новая газета», 2017).

Срастись. Просторечное. Например: Не срослось; Если срастется, то...; Как срастется, Всё срослось (устная речь).

При устранении субъектной валентности выявляется семантическая роль контрагента или бенефактива (участник, интересы которого непосредственно затрагивает ситуация, или который должен воспользоваться конечным результатом действия, но ни деятелем, ни пациенсом этой ситуации он не является).

\section{VI. Накопительно-объектный тип.}

Вкладываться / Вложиться. Семантическое новообразование: действительный залог, совершенный и несовершенный вид. Например: «Норникель» вложился в проект (ТВ, 22.06.2016); Москва предлагает инвесторам вложиться в транспортно-пересадочные узлы (газета «Аргументы и факты», 2016, № 5).

Преобразование:

- целевая валентность глагола;

- семантическая связь способа - как;

- глагол является объектом глагольного управления;

- наличие субъекта-деятеля. 
Структура семантики возвратной новации: субъект-деятель одушевленный; выделенная деятелем из себя предметная часть; приложение данной части к обозначаемому объекту-адресату.

Инвестироваться. Двувидовой глагол. Субъект-деятель одушевленный.

Определиться / Определяться.

В семантической новации устраняются две валентности глагола, функции и признака, и изменяется валентность субъекта. Появляется валентность деятеля-агенса, напр., Onределитесь уже (Интернет, 2016) и валентность пациенса - актанта, характеристики которого изменяются в результате действий другого лица, напр., Мь определились с экспертом (устная речь, 2017).

Интегрироваться. Действительный залог. Двувидовой глагол. Обстоятельственная связь - во что.

Закупаться. Действительный залог. Например, Мы закупаемся в субботу у знакомых фермеров (газета «Комсомольская правда», 01.01.2017).

Прикальваться / Приколоться. Просторечное. Структура значения: субъект одушевленный, результат, экспериенцер.

Проставляться. Просторечное. Например, Она будет проставляться в среду (устная речь).

В грамматической системе есть формы страдательного залога, которые не являются противопоставленными новообразованию соответствиями.

\section{VII. Притяжательно-возвратный тип.}

Образуется от переходных глаголов. Семантически соотносится с глаголами страдательного залога, но отличается по виду.

Распределиться. Например, По окончании университета он распределился в НИИЛМ.

Обсудиться. Разговорное. К примеру, Рабочая группа обсудится в следующем месяие.

Утвердиться. Разговорное. Например, Аспирант утвердился в декабре, т.е. представил желаемую тему / на заседании кафедры утвердили тему работы аспиранта.

Для этой группы не подходят трактуемые как рефлексивно-посессивные глаголы наподобие прищуриться, обозначающие действия, которые субъект-деятель совершает полностью для себя, в свою пользу, в своих интересах. Ср. пассивную интерпретацию, которая «предполагает, что данное действие субъект не может произвести над собою сам: Сам я преследовался в 1936 году за антифашистскую деятельность и был уволен из Института гибридизации (Гранин)» ${ }^{10}$.

Глаголы устно-разговорной сферы обсудиться и т.п. могут квалифицироваться как автокаузативные. Это вызвано различиями трактовки автокаузативности, относящейся к уровню синтаксиса ${ }^{11}$. Такая трактовка не совпадает с составом примеров типа спрятаться, познакомиться.

10 Ю.П. Князев. Русские возвратные глаголы..., с. 34.

11 Е.М. Лазуткина. О новой модели двусоставного глагольного предложения в современном 


\section{VIII. Деятельно-неперсональный тип.}

Глаголы имеют семантические актанты 'обладатель' и 'признак': Там пятнашка идется / бежится за 48 минут (устная речь). Ср. выраженный логический субъект-деятель и синтаксический объект - пациенс определенный: Ой, кому-то нынче плачется, а кому смеется (песня, 1974); Чтоб смеялось нам с утра (песня, 1935). Невыраженный субъект и деятель при выраженном объекте: Глаза встречаются, надолго изучаются, и так все ясно, слов не говори (песня, 1973).

Ср. с другой стороны глаголы с семантическими актантами 'способ' и 'цель': В кружок Анны Павловны принимались из франиузов только закоренелье легитимисты, и здесь выражалась патриотическая мысль... За военными событиями следилось жадно, и распускались самые выгодные для нашей армии слухи (Л. Толстой).

В субъектно-неопределенных возвратных глаголах подразумевается субъект-деятель; при этом он прямо не выражен и не выделен в структуре предложения, то есть присутствующий, но неопределенный и обобщенный. Функционировали деятельно-неперсональные глаголы с главной объектной связью, как то: Топоры, тесаки работали со всех сторон. Все делалось без приказания. Тащились дрова про запас ночи, пригораживались шалачики начальству, варились котелки, справлялись ружья и амуниция; Сражение дается. Убиваются тысячи людей с той и другой стороны (Л. Толстой). При главной объектной связи в той или иной степени подразумевается субъектная деятельность, причем она двупланова, особенно в варились котелки, убиваются тысячи людей.

В неперсональном употреблении отсутствуют критерии пассива. В современном русском языке не выступает дательный и творительный падеж - субъект при возвратном глаголе; нет именительного падежа - субъекта/подлежащего при обозначении физического действия. Например: $B$ городе действует несколько шалманов, где 100 гр выпивается за 40 р. (А. Болдырев. Осадная запись, 1948).

Обозначается объект действия возвратного глагола при неперсонифицированном субъекте, как то: Наших женщин так и не отучили носить национальную одежду - сари. В первую очередь по причине простоты. Покупается пять с половиной метров ткани и обматывается вокруг тела за секунды. Всё, платье готово (газета «Аргументы и факты», 2016, № 42). При этом глагольная форма единственного числа тяготеет к некоторому деятелю, предполагает обладателя действия, который дополнительно раскрывается контекстом за пределами предложения, так что лицо полагается, хотя в очень общем и неконкретизованном виде. Данный семантико-синтактико-словообразовательный тип в современном русском языке развивается. См.: Волосы мажутся керосином, потом они носятся прямые совсем (устная речь, 2017), т.е. волосы стоят прямо.

русском языке. [В:] Грамматические процессы и системы в синхронии и диахронии. Ред. колл. А.М. Молдован и др. Москва: Институт русского языка им. В.В. Виноградова РАН, 2016, с. 36. 
Таковы в целом основные грамматико-семантические типы возвратных глаголов, новации которых образуются и развиваются в современном русском языке. В современном русском языке также появляются, вне особых синтаксических предпосылок образования, возвратные глаголы - неологизмы, которые относятся к определенным выделявшимся ранее семантико-грамматическим группам. Например, новые взаимно-возвратные глаголы эсемеситься, чатиться; автокаузативные глаголы колбаситься (просторечное), подтянуться, к примеру, Отправляйся, и я скоро туда подтянусв; неагентивно-пассивные идентифицироваться, просчитываться; собственно возвратные глаголы позииионироваться/позиционировать себя, загружаться, скажем, Компьютер загружается, восстанавливаться, шугаться (просторечное).

При более тщательном и подробном рассмотрении выделяются подтипы возвратных глаголов. Они лексически более ограничены. Так, граница между отмечавшимся декаузативом и пассивом утрачивает четкие очертания в силу наличия «неавтономных» декаузативов ${ }^{12}$. Данная разновидность обозначает «неавтономную микроситуацию, являющуюся частью каузативной микроситуации» ${ }^{13}$, в которой лексическое значение основы глагола и семантический тип подлежащего указывают на то, что данная микроситуация не может возникнуть сама по себе. В таких глаголах агентивная ситуация представляется как неагентивная. Выделяются несколько типичных сфер, в которых используются «неавтономные» декаузативы. Это обозначения таких целенаправленных действия, в которых роль производителя действия состоит в их начальном импульсе, а дальнейшее их протекание происходит без его участия. Здесь размещаются также «неавтономные» декаузативные возвратные глаголы, называющие внешний эффект действия, производимого человеком, но его присутствие может быть незаметным.

Возникают еще менее распространенные, окказиональные явления возвратности. Например, областное просторечие: C Митькой Петровичем? Он ведь выпивается. Ох уж это не человек, если каждьй день бутылка (Н. Горланова. Ряженые, 1997).

Все рассмотренные явления глаголов суть лексика, т.е. значения, лексические связи и сочетаемость, и грамматика, грамматический уровень языка. Лексическая семантика, значение слов влияет на морфологическую синтагматику и на синтаксические отношения, возникающие между словами в предложении. В морфологии между общим значением процессуальности глагола и его типовыми акциональными значениями и значениями категорий залога, вида и наклонения, информирующих о связи предметов с предметами и качествами, существует глубокая внутренняя зависимость.

При обусловленности этими категориями функции морфемы -ся в образованных глаголах широки, богаты и разнообразны. Эти показатели связаны

12 Ю.П. Князев. Русские возвратные глаголь..., с. 34.

13 В.П. Недялков, Э.Ш. Генюшене, Типология рефлексивных конструкций. [В:] Теория функииональной грамматики: персональность; залоговость. Отв. ред. А.В. Бондарко. СанктПетербург: Наука, 1991, с. 262. 
с синтагматическими свойствами глаголов. На общей семантической карте рефлексивности в русском языке возвратные глаголы могут выражать все включаемые значения. Совокупность действительных продуктивных значений, связанных с функционированием возвратной морфемы в современном русском языке, показывает, что семантические проблемы категории возвратности имеют к лексикологии тесное отношение наряду с грамматикой. Система глагольных значений, связанных с постфиксом -ся, лишь частично основывается на субъектных и объектных отношениях действия. С ними соединились видовые значения действия, значение залога, а в связи с этим - синтагматические и синтаксические свойства и изменения и переходы лексических значений глагола.

Грамматико-семантическое описание дает понимание закономерностей строения парадигмы, связывающих разные формы в совокупность, и картины эволюции и перестройки парадигм; отмечается возникновение, существование и устранение менее регулярных и нерегулярных форм; изменение состава словопорождающих типов и их продуктивности; отмечается место и ранг элементов в парадигме, среди которых возможно различение исходных и более или менее важных форм.

\section{Литература}

Апресян Ю.Д. О толковом словаре управлений и сочетаемости русского глагола. [В:] Словарь, грамматика, текст. Москва: Институт русского языка им. Виноградова, 1996.

Виноградов В.В. Русский язык. Грамматическое учение о слове. Москва: Высшая школа, 1972.

Исследования по теории грамматики. Вып. 6: Типология аспектуальных систем и категорий. Ред. Е.В. Головко, М.А. Даниэль, В.А. Плунгян, Кс.П. Семёнова. Москва: Наука, 2012.

Князев Ю.П. Русские возвратные глаголы на семантической карте рефлексивности. [В:] Грамматические проиессы и системы в синхронии и диахронии. Ред. колл. А.М. Молдован и др. Москва: Институт русского языка им. В.В. Виноградова РАН, 2016.

Лазуткина Е.М. О новой модели двусоставного глагольного предложения в современном русском языке. [В:] Грамматические процессы и системы в синхронии и диахронии. Ред. колл. А.М. Молдован и др. Москва: Институт русского языка им. В.В. Виноградова РАН, 2016.

Малый академический словарь. Ред. А.П. Евгеньева. Москва: Русский язык, 1981-1984.

Недялков В.П., Генюшене Э.Ш. Типология рефлексивных конструкиий. [В:] Теория функииональной грамматики: персональность; залоговость. Отв. ред. А.В. Бондарко. СанктПетербург: Наука, 1991.

Русская грамматика. Т. 1-2. Ред. Н.Ю. Шведова. Москва: Высшая школа, 1980.

Современный русский титературный язык: учебник для студентов высших учебных заведений, обучающихся по направлению и спеииальности “Филология”. Ред. П.А. Лекант. Изд. 3-е, испр. и доп. Москва: Высшая школа, 1996.

Теоретические проблемы русского синтаксиса. Взаимодействие грамматики и словаря. Отв. Ред. Ю.Д. Апресян. Москва: Языки славянских культур, 2010.

Шанский Н.М., Бабайцева В.В. Современныци русский язык. В 3-х частях. Москва: Просвещение, 1987.

Haspelmath M. The geometry of grammatical meaning: semantic maps and cross-linguistic comparison. [B:] The new psychology of language. V. 2. Mahwah, NJ: Erlbaum, 2003. 